\title{
Trend detection Analysis of Seasonal Groundwater Levels in Arpa River Basin, Bilaspur District, Chhattisgarh, India
}

\author{
Gunja Dhruw $^{1 *}$, V. K. Tripathi ${ }^{1}$ and Bhupendra Dhankar ${ }^{2}$ \\ ${ }^{1}$ Department of Farm Engineering, Inst. of Agri. Sci., BHU, Varanasi (UP), India \\ ${ }^{2}$ Swami Vivekanand College of Agricultural Engineering and Technology and $R$ S, IGKV, \\ Raipur (CG) , India \\ *Corresponding author
}

\section{A B S T R A C T}

\section{Keywords}

Ground water level,

Trend analysis,

Mann-Kendall

t-test, Arpa River

basin

Article Info

Accepted:

18 May 2020

Available Online:

10 June 2020
Groundwater $(\mathrm{GW})$ trend analysis provides an early warning system for changes in water table caused by climatic conditions or in response to human activities such as water withdrawal. This analysis investigates the pattern and trends of the seasonal groundwater level data of Arpa River Basin in Bilaspur district, Chhattisgarh for the period from 1984 to 2015 . A study was under taken for identifying the trends in pre- and post-monsoon groundwater levels using non parametric Mann-Kendall test and Sen's slope estimator for time series modelling and forecasting of pre- and postmonsoon groundwater. The test has been used to analyze the groundwater data collected from the open/bore wells in the Arpa basin. For analysis using pre monsoon (May- June) and post monsoon groundwater data for six blocks of Bilaspur district. The result of the analysis shows that there is a decreasing trend in Belha block, but increasing trend observed in Masturi and Takhatpur block during pre and post monsoon season for the period of (1984-2015).

\section{Introduction}

Globally water resources of any region have become a major concern for planning and development of projects such as sustainable development of agricultural and food production projects, effective water resource management techniques and erosion and flood estimation and control methodologies etc. The available groundwater in the watershed is key factor, source of fresh water and important element for determining the availability of water to fulfil the different demand and agriculture mainly depends upon time of occurrence and amount of rainfall on any area to meets others numerous needs and demands such as hydropower water supply, industrial, domestic water supply. Changes in the land 
use and land cover scenario and rapid population growth are putting unavoidable stress over the water resources of the nation. The Indian aquifer system is facing an acute crisis due to the unscientific abstraction of groundwater for agricultural, industrial and domestic sector by the 1.3 billion growing population. Groundwater levels in several districts of agriculturally dominant states of Chhattisgarh have been declining at rapid rate. Bilaspur district in Chhattisgarh is famous for cultivation of export quality Dubraj rice. If declining trend of groundwater level continues in the district it will not only affect the sustainability of irrigated agriculture but also add to increase in energy consumption for groundwater pumping and $\mathrm{CO}_{2}$ emission.

A number of parametric and non-parametric tests have been used for trend detection. Parametric trend test requires data to be independent and normally distributed. On the other hand, a non-parametric test does not require the data to follow any particular statistical distribution and can tolerate outliers in the data (Hamed and Rao, 1998; Kisi and Ay, 2014). Hence, non-parametric tests are more suitable for non-normally distributed data, such as groundwater levels (Yue et al., 2002; Caloiero et al., 2011). The best known non-parametric test is based on the MannKendall's test and has been used by various researchers to understand long-term trends in groundwater levels (Tabari et al., 2011; Vousoughi et al., 2013; Machiwal and Jha, 2014; Ribeiro et al., 2014).

Helsel and Hirsch (1992) and Thakur and Thomas (2011) investigated the changes in the values of a random variable over some period of time using non-parametric test. Tabari (2011) determined the temporal trends in groundwater level using Mann Kendall's test and Sen's slope estimator. Machiwal (2013) identified the long-term trend of annual rainfall time series and pre-monsoon and post-monsoon groundwater levels. Ribeiro (2014) used Mann-Kendall's test to detect monthly trends of piezometric time series and their magnitude. The nonparametric Mann-Kendall (M-K) test (Mann 1945, Kendall 1975) is widely used to evaluate statistically significant trends in hydrological and climatological time series. The test assumes that the studied time series are stable, independent and random, with equal probability distributions. No assumption of normality is required. The test is recommended by the World Meteorological Organization for non-parametric analysis of the significance of monotonic trends. Examples of the use of the M-K test for detecting trends in climatic and hydrological time series data include the works of $\mathrm{Xu}$ et al., (2005) and Liu et al., (2008) for precipitation; $\mathrm{Xu}$ et al., (2006), Burn and Hesch (2007) and Bandyopadhyay et al., (2009) for evaporation and evapotranspiration; Douglas et al., (2000), Yue et al., (2003), Burn et al., (2004), Kahya and Kalayci (2004), Zhang et al., (2006), Wu et al., (2008) and Kumar et al., (2009) for streamflow; and Sprague and Lorenz (2009) for surface water quality. The non-parametric Mann-Kendall statistical test was used in this study for a monotonic and piece wise trend analyses of the long term groundwater levels of pre-monsoon and post-monsoon season over long period from 1984 to 2015of Bilaspur district Chhattisgarh.

\section{Materials and Methods}

\section{Study area}

The Arpa river sub-basin in the upper Mahanadi basin in Bilaspur district of Chhattisgarh is selected for study the significant trend in seasonal rainfall trend in long term (1984-2015). Arpa River is a main tributary of Mahanadi River which is known 
as the perennial source of irrigation in the state of Chhattisgarh. Making the lands of the state fertile from a very long time, Mahanadi intersects the various districts of Chhattisgarh. The Mahanadi river gives rise to Shivnath river which in turn gives rise to the Arpa river.

Arpa river is originated in Pendra (tehsil) in Bilaspur district at Khondari-Khongsara place. The length of Arpa is about $147 \mathrm{~km}$ and average water flow is $400 \mathrm{~m}$. River catchment area is 2022 sq.km. In $147 \mathrm{kms}$ of the river length, before meeting to Shivnath river it contributes more than $90 \mathrm{kms}$ to the forest area, including Bilaspur city and irrigated lands of this district. The water flows from north-west to south direction.

Except rainy season, it faces scarcity of water. The level of water raises 2-3 m up during rainy season and in summer season it moves $5 \mathrm{~m}$ down (Joshi et al., 2004). The river bed is mostly sandy having thickness of about $1.5 \mathrm{~m}$ and few rock exposures at some places.

\section{Data collection and analysis}

Pre-monsoon (May-June) and post-monsoon (October-November) groundwater data of Bilaspur district for the period of 1984 to 2015 were used for the analysis. The groundwater data collected from water resource department Madhya Pradesh.

\section{Methods of analysis}

\section{Mann-Kendall test}

The Mann Kendall (MK) commonly known as the Kendall's tau statistic, is a nonparametric test used for trend analysis. Mann (1945) first used this test and Kendall (1975) derived the test statistic distribution. The test has been suggested by the World Meteorological Organisation (WMO) to assess trends in environmental data time series (WMO 2014) as the test is suitable for cases where the trend may be assumed monotonic and therefore no seasonal aspects are presented in the data. The method is simple, does not require assuming normality, robust against outliers and can handle missing values (Hess et al., 2001). Accordingly, when compared to parametric test like t-test, the Mann-Kendall test has a higher power for nonnormally distributed data, which are normally presented in hydrological data (Yue and Pilon, 2004). It is worth to mention that some researchers (e.g. Sang et al., 2014) highlighted the need for pre-whitening of the time series data before conducting any trend analysis test, however, if the sample size is more than 70 then serial correlation does not affect the MK test (Basistha et al., 2009). The Mann-Kendall test calculates the slope of the line formed by plotting the variable of interest against time, but only considers the sign and not the magnitude of this slope. Hence, the MK test statistic is calculated from the sum of the signs of the slopes. The statistic $\mathrm{S}$ is:

$$
s=\sum_{i=1}^{n-1} \sum_{j=i+1}^{n-1} \operatorname{sgn}(x j-x i)
$$

Where, SisMann-Kendall statistic and sgn is the signum function. The application of trend test is done to a time series xi that is ranked from $\mathrm{i}=1,2 \ldots \mathrm{n}-1$ and $\mathrm{xj}$, which is ranked from $\mathrm{j}=\mathrm{i}+1,2 \ldots \ldots \ldots$ n. Where $X j$ and $X i$ are the consecutive series of data values, and $n$ is the length of the dataset. Each of the data point xi is taken as a reference point which is compared with the rest of the data point's $\mathrm{xj}$ so that,

$$
\operatorname{sgn}\left(x_{j}-x_{i}\right)=\left\{\begin{array}{c}
1 \text { if }\left(x_{j}-x_{i}\right)>0 \\
0 \text { if }\left(x_{j}-x_{i}\right)=0 \\
-1 \text { if }\left(x_{j}-x_{i}\right)<0
\end{array}\right\}
$$

At certain probability level $\mathrm{H}_{0}$ is rejected in favour of $\mathrm{H}_{1}$ if the absolute value of Sequ also 
$r$ exceeds a specified value $S \alpha / 2$, where $S \alpha / 2$ is the smallest $\mathrm{S}$ which has the probability less than $\alpha / 2$ to appear in case of no trend. A positive value of $S$ indicates an upward trend and negative value indicates downward trend (Salmi et al., 2002; Luo et al., 2008). For $\mathrm{n}=10$, the statistic $\mathrm{S}$ is approximately normally distributed with the mean $\mathrm{E}(\mathrm{s})=0$ and variance $(\operatorname{Var}(\mathrm{s}))$.

The Mann-Kendall test is based on the null hypothesis that a sample data is independent and identically distributed, which means there is no trend in the data points. Thus, if the null hypothesis the null hypothesis $\mathrm{H}_{0}$ is accepted at the significant level $\alpha$, then the mean and variance of the $S$ statistics are given by Kendall (1975) as it is approximately normally distributed, mean $(\mathrm{S})$ is zero.

Mean $(\mathbf{S})=0$

In the case where there are no ties in either ranking, the distribution of $S$ may be well approximated by a normal distribution with mean zero and variance as stated in Equation $\operatorname{Var}(\mathrm{S})=\frac{n(n-1)(2 n+5)}{18}$

In this method, the presence of a statistically significant trend is evaluated using the Zc value.

$$
Z_{c}=\left\{\begin{array}{l}
\frac{S-1}{\sqrt{\operatorname{Var}(S)}} \text { if } S>0 \\
0 \text { if } S=0 \\
\frac{S+1}{\sqrt{\operatorname{Var}(S)}} \text { if } S<0
\end{array}\right\}
$$

A positive value of $\mathrm{Zc}$ indicates an increasing trend and negative value indicates decreasing trend. The statistic Zc is normally distributed. To test an increasing or decreasing monotone trend, a two-tailed test at alevel of significance is used. Null hypothesis $\left(\mathrm{H}_{0}\right)$ is rejected if the absolute value of $\mathrm{Zc}$ is greater than Z1- $\alpha / 2$ where, $Z 1-\alpha / 2$ is obtained from the standard normal cumulative distribution tables. In this the null hypothesis $\left(\mathrm{H}_{0}\right)$ was that "there is no trend in time series of ground water levels". Where, $\alpha$ is the level of significance for the test and $\pm Z 1-\alpha / 2$ are the standard normal deviates. In this study, $\alpha$ and $\mathrm{Z} 1-\alpha / 2$ were taken as $5 \%$ and \pm 1.96 , respectively.

\section{Sen's slope estimator test}

If a linear trend is present in a time series, then the true slope (change per unit time) can be estimated using a simple nonparametric procedure developed by Sen (1968) 43. It has been widely used for determining the magnitude of the trend in hydrometeorological time series 48, 50. In this method, the slope estimates of $\mathrm{N}$ pairs of data are first calculated using the following expression as:

$$
Q_{i}=\frac{x_{j}-x_{k}}{j-k} \quad \text { for } i=1,2,3, \ldots \ldots, n
$$

where, $\mathrm{X}_{\mathrm{j}}$ and $\mathrm{Xk}$ are data values at time $\mathrm{j}$ and $\mathrm{k}(\mathrm{j}>\mathrm{k})$ respectively. The median of these $\mathrm{N}$ values of Qi is Sen's estimator of slope which is calculated as:

$$
\beta= \begin{cases}Q_{[(N+1[N / 2] / 2]} & \text { Nisodd } \\ \frac{1}{2}\left(Q+Q_{(N+2) / 2}\right) & \text { Niseven }\end{cases}
$$

A positive value of $\beta$ indicates an upward (increasing) trend and a negative value indicates a downward (decreasing) trend in the time series data.

\section{XLSTATE software}

The XLSTAT statistical analysis add-in offers a wide variety of functions to enhance the analytical capabilities of Excel, making it the 
ideal tool for your everyday data analysis and statistics requirements. Because it is quick, reliable, easy to install. XLSTAT has grown to be one of the most commonly used statistical software packages in the market. It relies on Excel for the input of data and the display of results, but the computations are done using autonomous software components. The use of Excel as an interface makes XLSTAT a user-friendly and highly efficient statistical and multivariate data analysis package. The quality of the computations is identical to that offered by classic scientific statistical analysis software.

\section{Kendall's Tau}

It is a coefficient that represents the degree of concordance between two columns of ranked data.

0 is no relationship.

1 is a perfect relationship.

From the value of Kendall's Tau, value of Z statistics is calculated by using formula:

$Z=\frac{3 \times \tan \sqrt{n(n-1)}}{\sqrt{2(2 n+5)}}$

Where $\mathrm{n}=$ number of samples

\section{Variance}

It measures how far a set of random number are spread out from their average from its mean Variance is given by:

$\operatorname{Var}(\mathrm{S})=\frac{n(n-1)(2 n+5)}{18}$

Where $\mathrm{n}=$ number of samples

\section{P-value}

A $p$-value helps you determine the significance of your results. All hypothesis tests ultimately use a $p$-value to weigh the strength of the evidence (what the data are telling you about the population).

The $p$-value is a number between 0 and 1 and interpreted in the following way:

A small $p$-value (typically $\leq 0.05$ ) indicates strong evidence against the null hypothesis, so you reject the null hypothesis.

\section{Results and Discussion}

Continuous records of pre and post-monsoon water levels are important to study the water table fluctuation trends and access the ground water potential. The differences between pre and post-monsoon water levels, represents the combined effect of groundwater recharge and draft in a region. The results obtained from the Mann-Kendall test was used to establish the trends in time series of pre-monsoon and post- monsoon ground water levels. Results obtained from analysis of time series data using XLSTAT Software were used for forecasting. The observed Groundwater levels in 20 observation wells of Six blocks in Arpa river basin as shown in Fig. 2

\section{Water table fluctuations trends}

To determine the trend in time series data on pre and post-monsoon groundwater levels in different blocks of Bilaspur district, MannKendall statistics (Zc statistics) were determined. Values of $\mathrm{Zc}$ for different blocks for pre- monsoon and post-monsoon water levels varied from $-7.25 \mathrm{~mm}$ to $5.40 \mathrm{~mm} /$ year and $-7.38 \mathrm{~mm}$ to $6.23 \mathrm{~mm} /$ year respectively which shown in Table $2 \& 3$

The results of Mann-Kendall t test carried out for six blocks included in this analysis shows that, there is negative increasing trend in most of blocks at $5 \%$ significant level. 
Table.1 Block wise well location of Arpa basin Bilaspur district

\begin{tabular}{|c|c|c|c|c|c|c|}
\hline S.No. & Well No. & Well type & District & Tehsil & Block & Village \\
\hline 1. & BSP-005-OW & Dug well & Bilaspur & Gaurela & Gaurela & Keonchi \\
\hline 2. & BSP-006-OW & Dug well & Bilaspur & Gaurela & Gaurela & Khodri \\
\hline 3. & BSP-012-OW & Dug well & Bilaspur & Takhatpur & Takhatpur & Ganiyari \\
\hline 4. & BSP-013-OW & Dug well & Bilaspur & Takhatpur & Takhatpur & Ghutkoo \\
\hline 5. & BSP-023-OW $\{\mathrm{A}\}$ & Dug well & Bilaspur & Takhatpur & Takhatpur & Sakri \\
\hline 6. & BSP-015-OW & Dug well & Bilaspur & Kota & Kota & Kata \\
\hline 7. & BSP-018-OW & Dug well & Bilaspur & Kota & Kota & Ratanpur \\
\hline 8. & BSP-019-OW & Dug well & Bilaspur & Kota & Kota & Belgahna \\
\hline 9. & BSP-020-OW & Dug well & Bilaspur & Kota & Kota & Khonsara \\
\hline 10. & BSP-021-OW & Dug well & Bilaspur & Belha & Belha & Bartori \\
\hline 11. & BSP-022-OW & Dug well & Bilaspur & Belha & Belha & Belha \\
\hline 12. & BSP-023-OW & Dug well & Bilaspur & Belha & Belha & Bilaspur \\
\hline 13. & BSP-023-OW & Dug well & Bilaspur & Belha & Belha & Semarta \\
\hline 14. & BSP-024-OW & Dug well & Bilaspur & Belha & Belha & Semarta \\
\hline 15. & BSP-025-OW & Dug well & Bilaspur & Belha & Belha & Chakrabhata \\
\hline 16. & BSP-025-OW $\{\mathrm{A}\}$ & Dug well & Bilaspur & Belha & Belha & Chakrabhata \\
\hline 17. & BSP-026 & Dug well & Bilaspur & Belha & Belha & Beltara \\
\hline 18. & BSP-031 & Dug well & Bilaspur & Masturi & Masturi & Seepat \\
\hline 19. & BSP-031\{A\} & Dug well & Bilaspur & Masturi & Masturi & Seepat \\
\hline 20. & KOB-001 & Dug well & Korba & Pali & Pali & Pali \\
\hline
\end{tabular}

Table.2 Pre-monsoon groundwater levels observed from various block well

\begin{tabular}{|c|c|c|c|c|c|c|c|c|}
\hline $\begin{array}{l}\text { Sr. } \\
\text { No. }\end{array}$ & $\begin{array}{l}\text { Block } \\
\text { name }\end{array}$ & $\begin{array}{l}\text { Mann } \\
\text { Kendall } \\
\text { Statistic(S) }\end{array}$ & $\begin{array}{l}\text { Kendall's } \\
\operatorname{tau}(\tau)\end{array}$ & Variance & $\begin{array}{l}\text { Z } \\
\text { Statistics }\end{array}$ & P value & $\begin{array}{l}\text { Sen's } \\
\text { slope } \\
\text { magnitude }\end{array}$ & $\begin{array}{l}\text { Inference } \\
\text { drawn }\end{array}$ \\
\hline 1. & Gaurela & 49.00 & 0.106 & 3455.0 & 0.9137 & 0.414 & 0.016 & $\mathbf{T}$ \\
\hline 2. & Gaurela & 176.0 & 0.356 & 3800.0 & 2.6649 & 0.005 & 0.133 & $\mathbf{T}$ \\
\hline 3. & Takhatpur & -82.00 & -0.190 & 3131.3 & -1.6822 & 0.148 & -0.034 & 1 \\
\hline 4. & Takhatpur & -76.00 & -0.175 & 3140.6 & 6.7287 & 0.181 & -0.038 & $\mathbf{t}$ \\
\hline 5. & Takhatpur & 27.00 & 0.257 & 408.3 & 6.2271 & 0.198 & 0.177 & $\mathbf{T}$ \\
\hline 6. & Kota & -206.0 & -0.448 & 3456.0 & -3.6998 & 0.000 & -0.063 & $\downarrow$ \\
\hline 7. & Kota & -102.0 & -0.235 & 3138.6 & -2.0474 & 0.071 & -0.024 & I \\
\hline 8. & Kota & -302.0 & -0.016 & 3800.6 & -4.7887 & $<0.0001$ & -0.17 & 1 \\
\hline 9. & Kota & 63.00 & 0.127 & 3799.6 & 1.0247 & 0.315 & 0.016 & $\boldsymbol{t}$ \\
\hline 10. & Belha & -5.00 & -0.012 & 3139.6 & 0.6655 & 0.943 & -0.002 & $\mathbf{t}$ \\
\hline 11. & Belha & -174.0 & -0.375 & 3458.6 & -2.5349 & 0.003 & -0.032 & $\downarrow$ \\
\hline 12. & Belha & 6.00 & 0.050 & 491.3 & 4.6264 & 0.822 & 0.018 & $\mathbf{t}$ \\
\hline 13. & Belha & 17.00 & 0.162 & 408.3 & 2.5298 & 0.428 & 0.113 & $\boldsymbol{1}$ \\
\hline 14. & Belha & -76.00 & -0.633 & 493.0 & -7.3753 & 0.001 & -0.074 & I \\
\hline 15. & Belha & 10.00 & 0.128 & 268.0 & -3.1299 & 0.583 & 0.063 & $\downarrow$ \\
\hline 16. & Belha & -73.00 & -0.611 & 492.0 & -3.3921 & 0.001 & 0.189 & I \\
\hline 17. & Belha & -68.00 & -0.147 & 3458.0 & -1.7731 & 0.255 & -0.035 & I \\
\hline 18. & Masturi & -10.00 & -0.074 & 589.00 & -5.5470 & 0.711 & -0.125 & $\downarrow$ \\
\hline 19. & Masturi & -80.00 & -0.776 & 407.34 & -6.8944 & $<0.0001$ & -0.1 & I \\
\hline 20. & Pali & -244.0 & -0.647 & 2560.0 & -5.4922 & $<0.0001$ & -0.089 & $\downarrow$ \\
\hline
\end{tabular}


Table.3 Post-monsoon ground water level observed from various block wells

\begin{tabular}{|c|c|c|c|c|c|c|c|c|}
\hline $\begin{array}{l}\text { Sr. } \\
\text { No. }\end{array}$ & $\begin{array}{l}\text { Block } \\
\text { name }\end{array}$ & $\begin{array}{l}\text { Mann } \\
\text { Kendall } \\
\text { Statistic(S) }\end{array}$ & $\begin{array}{l}\text { Kendall's } \\
\operatorname{tau}(\tau)\end{array}$ & Variance & $\begin{array}{l}Z \\
\text { Statistics }\end{array}$ & $P$ value & $\begin{array}{l}\text { Sen's } \\
\text { slope } \\
\text { magnitude }\end{array}$ & $\begin{array}{l}\text { Inference } \\
\text { drawn }\end{array}$ \\
\hline 1. & Gaurela & 49.00 & 0.106 & 3455.0 & 0.9137 & 0.414 & 0.016 & $\boldsymbol{1}$ \\
\hline 2. & Gaurela & 176.0 & 0.356 & 3800.0 & 2.6649 & 0.005 & 0.133 & $\boldsymbol{1}$ \\
\hline 3. & Takhatpur & -82.00 & -0.190 & 3131.3 & -1.6822 & 0.148 & -0.034 & 1 \\
\hline 4. & Takhatpur & -76.00 & -0.175 & 3140.6 & 6.7287 & 0.181 & -0.038 & 1 \\
\hline 5. & Takhatpur & 27.00 & 0.257 & 408.3 & 6.2271 & 0.198 & 0.177 & 1 \\
\hline 6. & Kota & -206.0 & -0.448 & 3456.0 & -3.6998 & 0.000 & -0.063 & $\downarrow$ \\
\hline 7. & Kota & -102.0 & -0.235 & 3138.6 & -2.0474 & 0.071 & -0.024 & 1 \\
\hline 8. & Kota & -302.0 & -0.016 & 3800.6 & -4.7887 & $<0.0001$ & -0.17 & 1 \\
\hline 9. & Kota & 63.00 & 0.127 & 3799.6 & 1.0247 & 0.315 & 0.016 & 1 \\
\hline 10. & Belha & -5.00 & -0.012 & 3139.6 & 0.6655 & 0.943 & -0.002 & $\uparrow$ \\
\hline 11. & Belha & -174.0 & -0.375 & 3458.6 & -2.5349 & 0.003 & -0.032 & 1 \\
\hline 12. & Belha & 6.00 & 0.050 & 491.3 & 4.6264 & 0.822 & 0.018 & 1 \\
\hline 13. & Belha & 17.00 & 0.162 & 408.3 & 2.5298 & 0.428 & 0.113 & 1 \\
\hline 14. & Belha & -76.00 & -0.633 & 493.0 & -7.3753 & 0.001 & -0.074 & 1 \\
\hline 15. & Belha & 10.00 & 0.128 & 268.0 & -3.1299 & 0.583 & 0.063 & $\downarrow$ \\
\hline 16. & Belha & -73.00 & -0.611 & 492.0 & -3.3921 & 0.001 & 0.189 & 1 \\
\hline 17. & Belha & -68.00 & -0.147 & 3458.0 & -1.7731 & 0.255 & -0.035 & $\downarrow$ \\
\hline 18. & Masturi & -10.00 & -0.074 & 589.00 & -5.5470 & 0.711 & -0.125 & 1 \\
\hline 19. & Masturi & -80.00 & -0.776 & 407.34 & -6.8944 & $<0.0001$ & -0.1 & 1 \\
\hline 20. & Pali & -244.0 & -0.647 & 2560.0 & -5.4922 & $<0.0001$ & -0.089 & $\downarrow$ \\
\hline
\end{tabular}

Fig.1 Index map of Arpa River basin

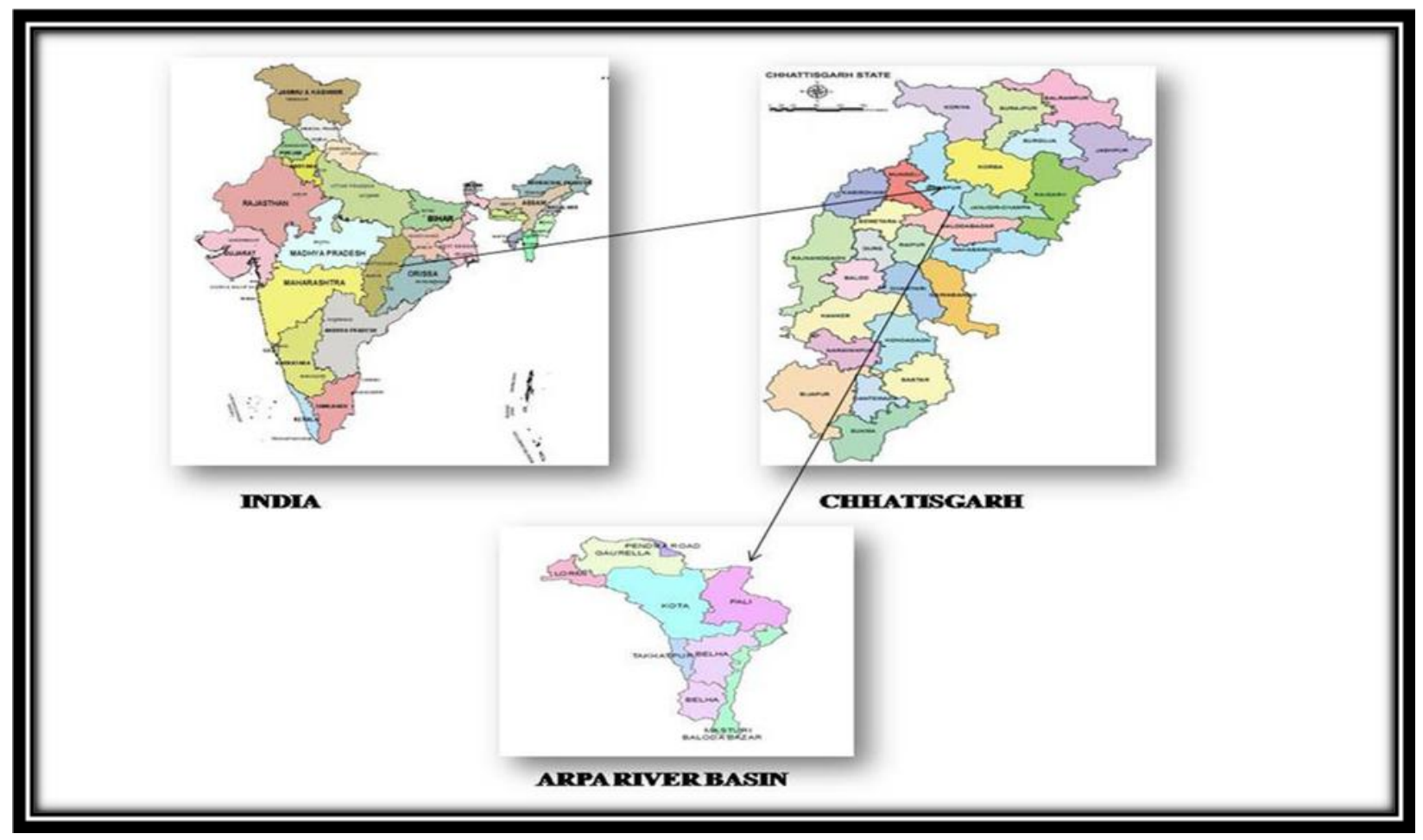


Fig.2 Pre monsoon and post monsoon groundwater levels of six blocks of Arpa River Basin
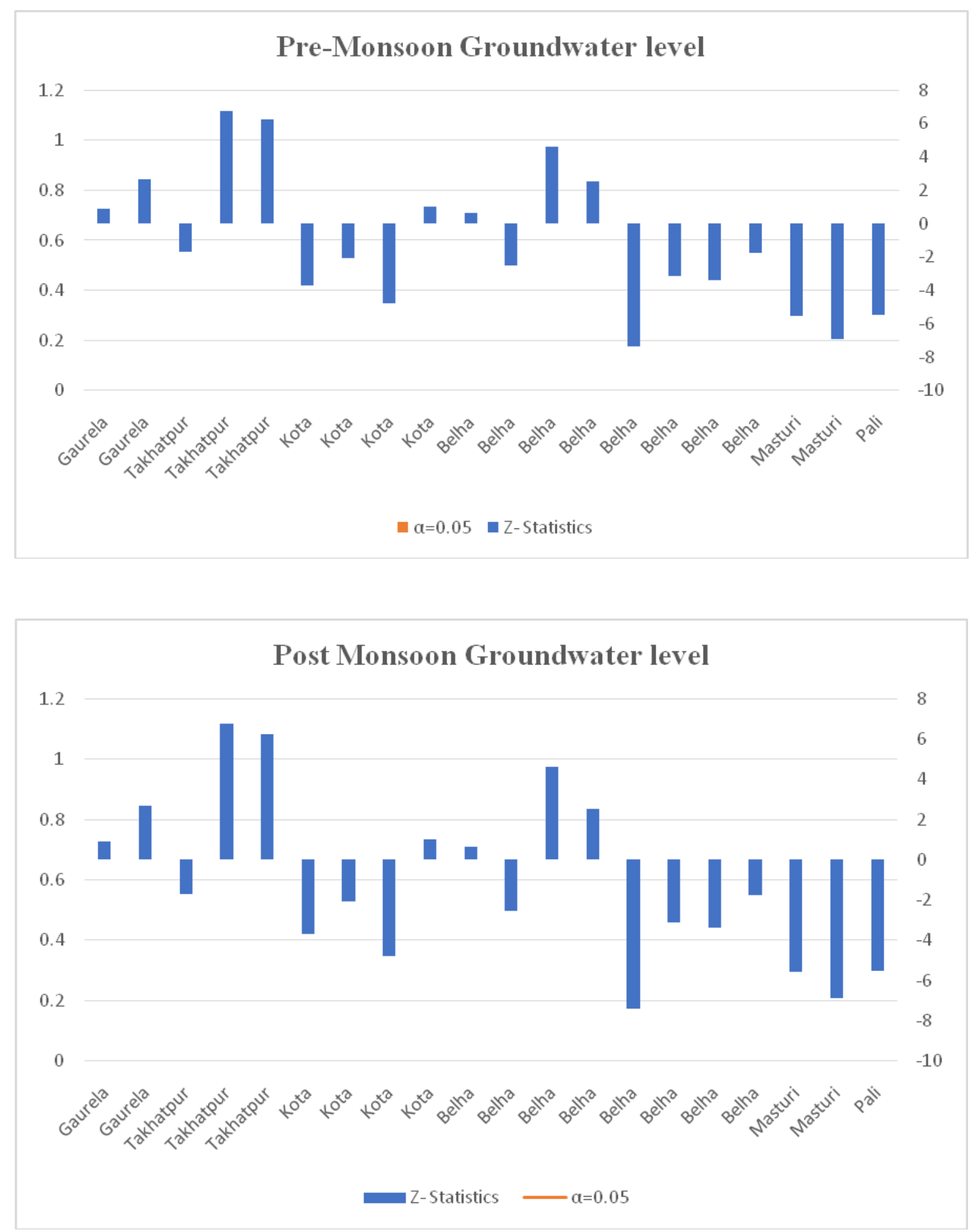
Fig.3 Zmk statistics and Sen's Slope magnitude for pre monsoon ground water level

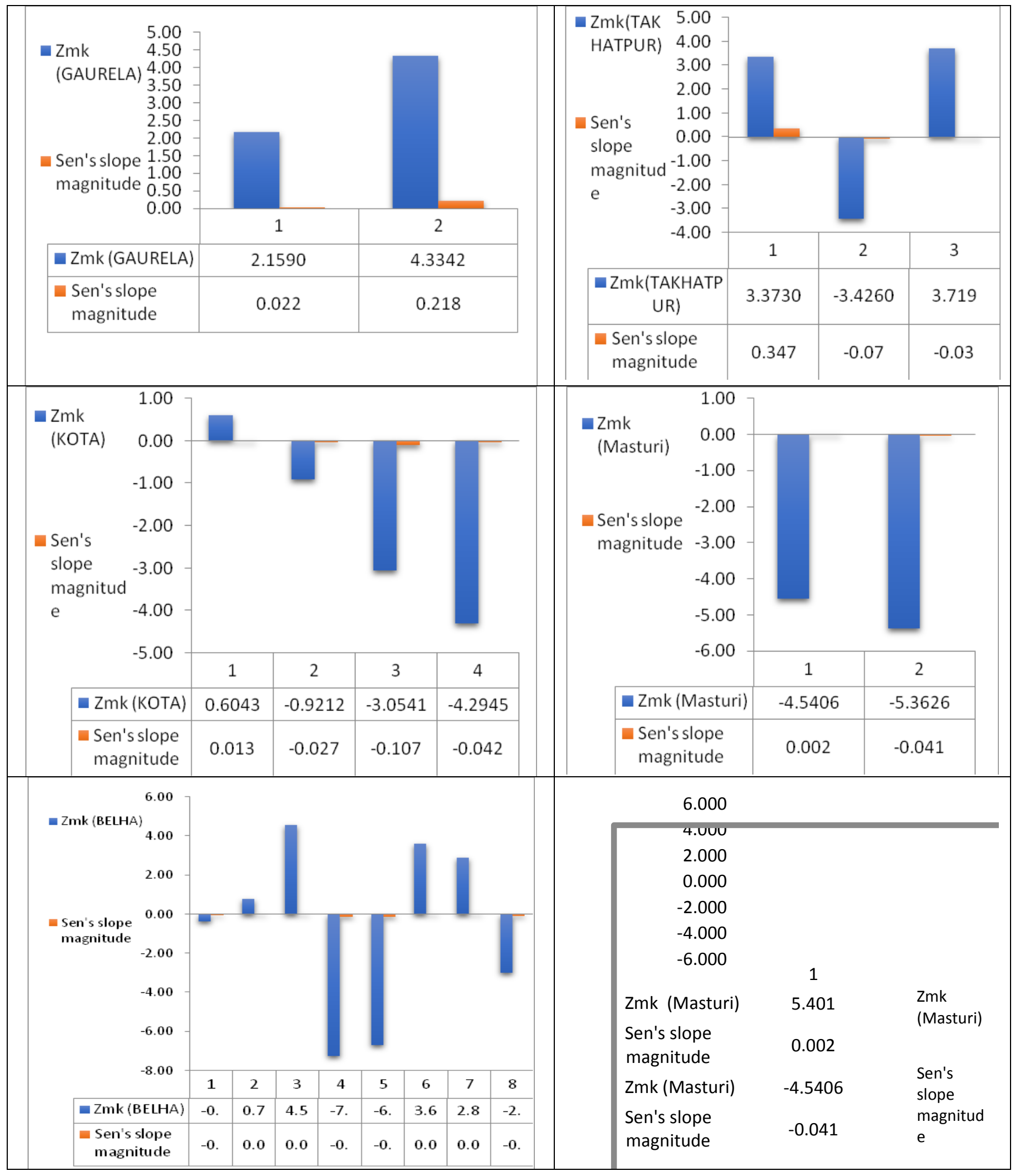


Fig. 4 Zmk statistics and Sen's Slope magnitude for post monsoon ground water level

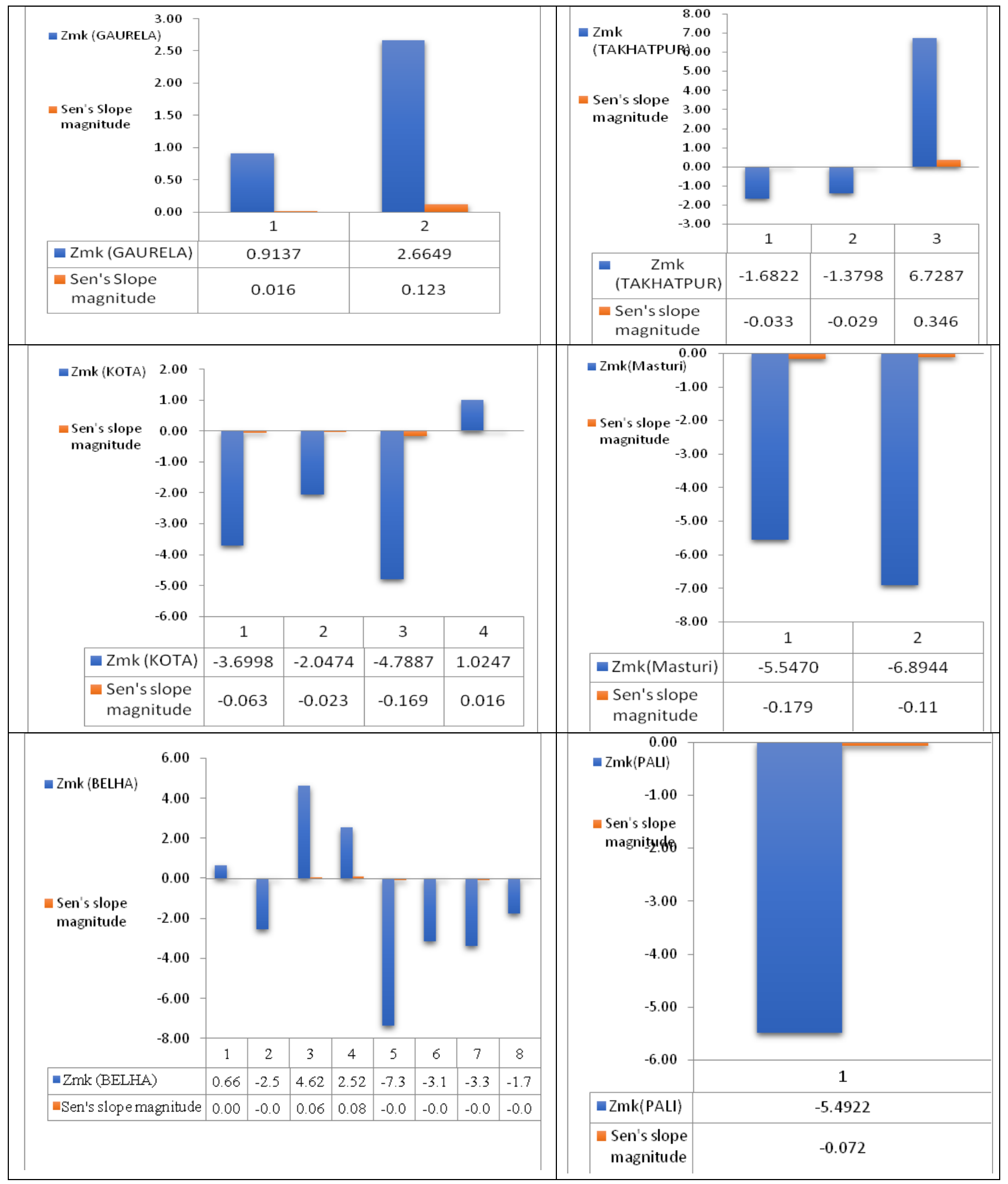


The result of the analysis shows that there is a negative increase in trends for the groundwater level of 1996 to 1998 which is $7.2454 \mathrm{~mm}$ in Belha and positive increase in trends 5.401mm in Masturi during 2000-2002 in Pre monsoon season.

In Post monsoon there is negative increase in trends between1996-1998 which is -7.3753 $\mathrm{mm}$ in Belha but slight increase during 19982000 but there are also positively increasing trends during 1987 to 1988 which is 6.7287 $\mathrm{mm}$ in Takhatpur block.

This indicated that there was a significant trend in time series data of pre and postmonsoon groundwater levels. The positive sign suggests that groundwater levels are declining with respect to the ground surface. After identifying the trend, Sen's slope estimator was used to find out the slope of trend line (i.e. rate of water level decline, $\mathrm{mm} / \mathrm{yr}$ ).

Positive value of slope indicated the declining trend (i.e. depth of water level with respect to ground surface is increasing) of groundwater level during the period of 1984-2015.

In conclusion, water resource has become a prime concern for existence and improvement of life, it depends on river basin. In the present study groundwater level trend in the Arpa river basin was assessed with MannKendall test for various blocks of Bilaspur district. Mann Kendall's trend test was used to explore the trend in groundwater levels for a network of 20 observation wells obtained from Water Resource Department for both pre-monsoon and post-monsoon seasons. Results from the test indicate that Belha block having extremely decreasing trend during Pre and Post monsoon session but there is increasing in ground water level in Masturi block and Takhatpur block during Pre and Post monsoon respectively. In order to avoid groundwater depletion, groundwater development needs to be implemented in a planned manner to prevent adverse impacts on groundwater. An artificial recharge can be implemented to avoid the declining trend in groundwater levels. Water-logging and soil salinity problems, resulting from the gradual rise of ground water levels, are observed in many canal command areas due to surface water irrigation without environmental considerations. Therefore, a conjunctive water use strategy in areas experiencing waterlogging problems needs to be adopted.

\section{Acknowledgment}

The authors are immensely grateful to Water Resource Department, Madhya Pradesh, for providing groundwater level data. The authors express their sincere thanks to Dr. T.R. Nayak Sr. Scientist National Institute of Hydrology Bhopal for providing the detail information regarding improvement of research work.

\section{References}

Bandyopadhyay et al., (2009). Temporal trends in estimates of reference evapotranspiration over India. Journal of Hydrologic Engineering, 14(5):508515.

Basistha et al., (2009) Analysis of historical changes in Rainfall in the Indian Himalayas. International Journal of Climatology. 29: 555-572.

Burn et al., (2004). Detection of Hydrologic trends and variability. Journal of Hydrology 255(1-4):107-122.

Caloiero et al., (2011). Trend detection of annual and seasonal rainfall in Calabria (Southern Italy). International Journal of Climatology 31(1):44-56.

Helsel and Hirsch (1992) Statistical methods in Water resources Book. January.

Hamed et al., (1998) Trend Test in reference evapotranspiration using Mann Kendall 
and Spearsman's Rho test in arid region of Iran. Springer Water resource management, 26: 211-224.

Hesch (2007) Analysis trends in reference evapotranspiration and weather variables in the Tons river basin in central India. Stochastic research environment and risk assessment. 27: 1407-1421.

Hess et al., (2001) Spatial and Temporal trend analysis of long-term rainfall records in data poor catchments with missing data, a case study of lower shire floodplain in Malawi for the period 1953-2010. Hydrology and Earth Sciences System Discussions.

Kisi and Ay (2014). Analysis of rainfall trends and its spatial patterns during the last over the Gangetic West Bengal, Eastern India. Journal of Geovisualization and Spatial analysis.

Machiwael (2013). Rainfall trends in twentieth century over Kerala, India, Journal of Atmospheric Environment :43.

Rao (1998). A modified Mann Kendall trend test for autocorrelated data. Journal of Hydrology Volume 204, issues 1-4, 30 January 1998: 182-196

Ribeiro (2014). Evaluating piezometric trends using the Mann Kendall test on the alluvial aquifers of the Elqui River basin, Chile Hydrological Sciences Journal, 50:1, -93.

Salmi et al., (2002). Detecting trends of annual values of atmospheric pollutants by the Mann Kendall test and Sen's Slope estimates the Excel template application MAKESENS.

Sprague and Lorenz (2009). Journal of Environment Sciences and Technology Regional Nutrient Trends in Streams and river of United States, 1993-2003 43, 10: 3430-3435.

Tabari (2011). Long term variation of Water quality in the Maroon River Iran. Journal of Environmental monitoring and assessment 177(1-4): 273-87

Thakur and Thomas (2011). Journal of Geological Society of India. Vol.77, April:303-308.

Yue et al., (2002). The influence of autocorrelation on the ability to detect trend in hydrological series. Hydrological Processes 16:1807-1829.

Xu et al., (2005). Homogeneity tests and nonparametric analysis of tendencies in precipitation time series in Keszethly, Western Hungary. J. Theoretical and applied Climatology, 139: 849-859.

\section{How to cite this article:}

Gunja Dhruw, V. K. Tripathi and Bhupendra Dhankar. 2020. Trend detection Analysis of Seasonal Groundwater Levels in Arpa River Basin, Bilaspur District, Chhattisgarh, India. Int.J.Curr.Microbiol.App.Sci. 9(06): 1425-1436. doi: https://doi.org/10.20546/ijcmas.2020.906.178 